\title{
PARTICIPAÇÃO DA COMUNIDADE EM ÓRGãos da AdMINISTRAÇÃo PÚBLICA
}

Maria Sylvia Zanella Di Pietro ${ }^{* \prime}$

\section{ESTADO DE DIREITO DEMOCRÁTICO}

A idéia de participação da comunidade na gestão e no controle da Administração Pública ganhou força com a instauração do chamado Estado de Direito Democrático.

Se for analisada a evolução do Estado de Direito, verifica-se que, em sua fase inicial, no período do Estado Liberal, prega-se a separação entre o Estado e a sociedade civil; dentro de sua órbita de atuação - em especial nas relações internacionais e na manutenção da ordem pública - o Estado devia ser forte, dispondo, inclusive, de aparelhamento coativo indispensável para atingir essas finalidades. Mas na esfera própria da sociedade civil em especial no domínio econômico - o Estado não devia intervir, já que a grande preocupação consistia em proteger os direitos individuais e a liberdade de iniciativa. Isto gera uma separação muito nítida entre as idéias de serviço público e atividade privada; entre direito público e direito privado.

Não obstante a apregoada separação entre o Estado e a sociedade, entre 0 serviço público e a atividade privada, entre o direito público e o direito privado, o fato é que se verificou considerável crescimento da Administração Pública, forçando a utilização de vários institutos pelos quais o particular exercia determinados serviços públicos mediante delegação do poder público, como a concessão de serviço público, a atribuição de prerrogativas a titulares de certas profissões, como intérpretes oficiais, tradutores públicos, leiloeiros, notários, comandantes de navios, etc.

A partir da segunda metade do século XIX, começa uma imensa transformação da Administração Pública, que se acentuaria notavelmente depois da Segunda Guerra Mundial, dando nascimento a uma segunda fase do Estado de Direito, ou seja, à fase do Estado Social de Direito, em que o Estado se transforma em prestador de serviços, para atender às inúmeras deman-

(") Professora Titular de Direito Administrativo na Faculdade de Direito da Universidade de São Paulo. 
das da coletividade. Segundo Mariano Baena de Alcázar (in "Curso de Ciencia de la Administración", Madri, Tecnos, 1985, vol. 1, pp. 80 e ss.), é possível que o fator chave dessa transformação seja a passagem do Estado monoclasse para o Estado pluriclasse, com tudo o que isso significa em termos de necessidade de satisfazer às demandas crescentes que se colocam perante o Estado, no terreno econômico e social, pela totalidade da população e não só pelas classes privilegiadas. Já não se fala mais em interesse público apenas, mas em vários interesses públicos, representativos dos vários setores da sociedade civil.

A conseqüência foi a multiplicação dos interesses públicos, dos interesses difusos, dos interesses coletivos, a diminuição da separação entre Estado e sociedade, e o aumento da colaboração do particular com a Administração Pública. Por outro lado, a proteção do interesse público deixou de ser prerrogativa do Estado, que não tinha condições de assumir todas as novas atividades de interesse geral; passou-se a falar em "privatização do interesse geral".

Com relação a essa multiplicidade de novas atividades, o Estado assumiu diferentes atitudes:

a) algumas dessas atividades, ele assumiu como serviços públicos, entrando na categoria de serviços públicos comerciais, industriais e sociais do Estado; para desempenhar esses serviços, o Estado passou a criar maior número de empresas estatais e fundações;

b) outras atividades, também de natureza econômica, o Estado deixou na iniciativa privada, mas passou a exercê-las a título de intervenção no domínio econômico, por meio de sociedades de economia mista, empresas públicas e empresas sob controle acionário do Estado;

c) o terceiro tipo de atitude que o Estado assumiu foi o que se verificou em relação a certas atividades de interesse público que o Estado nem definiu como serviço público, nem passou a exercer a título de intervenção; ele as deixou na iniciativa privada e limitou-se a fomentá-las, por meio de auxílios e subvenções pagos pelos cofres públicos, financiamentos para quem quisesse realizar obras de interesse social, isenções fiscais, desapropriações por interesse social.

A característica principal desse tipo de prestação de atividade de interesse público é justamente a colaboração com o poder público. É uma atividade paralela ao Estado, ou seja, é uma atividade paraestatal. Seria aquilo que André de Laubadère (citado por Françoise Roque, in "Revue du Droit Public", 1990, n. 6, p. 1785) considera como uma atividade que atua na vizinhança com o serviço público. Ela não é serviço público e não é atividade inteiramente privada. Ela está numa zona intermediária.

Nas palavras de Bernard Gény, em seu Essai d'une théorie génerale de la collaboration des administrés avec l'administration (apud Françoise Ro- 
que, ob. cit., p. 1785), "se a administração não tem o monopólio do bem público, se ela não tem vocação exclusiva para satisfazer às necessidades gerais da coletividade, disso resulta que os particulares podem, paralelamente a ela, por seus próprios meios, perseguir os mesmos fins".

Mas a evolução do Estado de Direito não parou aí. Chegou-se a uma terceira fase, a do chamado Estado Democrático de Direito. Nesse período, a participação do particular já não se dá mais nem por delegação do poder público, nem por simples colaboração em uma atividade paralela. Ela se dá mediante a atuação do particular diretamente na gestão e no controle da Administração Pública. É nesse sentido que a participação popular é uma característica essencial do Estado de Direito Democrático, porque ela aproxima mais o particular da Administração, diminuindo ainda mais as barreiras entre o Estado e a sociedade.

De um lado, há de se realçar a existência de grupos na sociedade, que procuram relacionar-se com o Estado, procuram influenciar as decisões do Estado e, em especial, da Administração Pública; é o caso dos partidos políticos, dos sindicatos, das grandes empresas, dos grupos empresariais. Muitos deles atuam como grupos de pressão, contrariamente aos princípios da democracia, já que não buscam o benefício coletivo, mas o seu próprio benefício.

Mas há um segundo dado a realçar, que é a possibilidade de participação do próprio cidadão, individualmente considerado.

A esse respeito, cabe assinalar que vivemos em uma sociedade pluralista; por isso mesmo, não se pode dizer que apenas os grandes grupos têm possibilidade de participar. Os representantes dos vários setores da sociedade devem ter a mesma possibilidade. E nós vivemos também em um sistema em que se adota o princípio da liberdade individual, de maneira que ninguém é obrigado a filiar-se a um determinado grupo. Isto está expresso na Constituição de 1988, em dois dispositivos: no art. 50, quando diz que ninguém é obrigado a associar-se ou a permanecer associado; e no art. $8^{\circ}$, segundo o qual ninguém é obrigado a filiar-se a sindicato. Assim, essa participação do cidadão individualmente considerado é a mais importante, em termos de participação popular na Administração Pública.

Na realidade, a expressão "Estado de Direito Social e Democrático" designa três fases do Estado de Direito, que não se desenvolveram de modo que uma substituisse a outra, mas de modo que em cada qual se acrescentasse um elemento novo: o Estado de Direito, em sua fase inicial, protegia os direitos individuais e a liberdade de iniciativa, pregando a separação entre Estado e sociedade; o Estado Social, sem deixar de lado os direitos individuais, acrescenta os direitos sociais (que exigem a atuação do Estado) e a preocupação com os interesses públicos, cuja tutela já se reconhece caber conjuntamente ao Estado e à sociedade; o Estado Democrático trouxe a idéia de participação do cidadão na Administração Pública, combatendo a sepa- 
ração entre Estado e sociedade e pregando a adoção de uma Administração menos autoritária, menos centralista, menos hierarquizada, mais próxima do cidadão.

Segundo Antonio Enrique Pérez Luño (in "Derechos humanos, Estado de derecho y Constitución", Madri, Tecnos, 1986, pp. 227-8), esse aspecto democrático do Estado de Direito implica:

1. afirmação da necessária continuidade entre os princípios social e democrático e o Estado de Direito, no sentido de que não há oposição entre uma idéia e outra;

2. reconhecimento da abolição fática da separação entre o Estado e a sociedade;

3. "superação do caráter negativo dos direitos fundamentais que deixam, deste modo, de ser considerados como autolimitação do poder soberano do Estado, para tornarem-se limites da atuação estatal para transformar-se em instrumentos jurídicos de controle de sua atividade positiva, que deve estar orientada para possibilitar a participação dos indivíduos e dos grupos no exercício do poder. O que traz como conseqüência a necessidade de incluir no sistema dos direitos fundamentais não só as liberdades clássicas mas também os direitos econômicos, sociais e culturais como categorias acionáveis e não como meros postulados programáticos";

4. exigência de que a interpretação do Estado Social de Direito não responda a um modelo centralista, rígido e monolítico, mas que funcione através de formas pluralistas que possibilitem e articulem a participação das pessoas e dos grupos no processo político, econômico, social e cultural; com esse objetivo, deve o Estado propiciar e estimular as formas de autogestão e auto-organização da economia e da estrutura social;

5. manutenção do princípio da supremacia do direito, embora não mais na concepção formalista, vazia de conteúdo e eficácia, própria do positivismo jurídico.

No que diz respeito à Administração Pública, a democratização exige, entre outras medidas:

1. substituição das estruturas hierárquico-autoritárias por formas de deliberação colegial;

2. introdução do voto na seleção das pessoas a quem forem confiados cargos de direção individual;

3. participação paritária de todos os elementos que exerçam a sua atividade em determinados setores da Administração; 
4. transparência ou publicidade do processo administrativo;

5. gestão participada, ou seja, participação dos administrados através de organizações populares de base e de outras formas de representação na gestão da administração pública (cf. José Joaquim Gomes Canotilho, "Direito Constitucional", Coimbra, Livraria Almedina, 1989, p. 368).

\section{FORMAS DE PARTICIPAÇÃO DA COMUNIDADE}

A Constituição brasileira de 1988 , coerente com a consagração, no art. $1^{\circ}$, do Estado Democrático de Direito, previu vários instrumentos que permitem a participação, direta ou direta, do cidadão na Administração Pública, dos quais se podem citar principalmente os seguintes:

1. direito à informação (art. $\left.5^{\circ}, X X X \mid I I\right) ;$

2. mandado de injunção (art. $5^{2}$, LXXI);

3. ação popular (art. 5, LXXIII);

4. habeas data (art. 50, LXXII);

5. participação dos trabalhadores e empregadores nos colegiados dos órgãos públicos em que seus interesses profissionais ou previdenciários sejam objeto de discussão e deliberação (art. 10);

6. publicidade dos atos da Administração Pública;

7. direito de o cidadão denunciar irregularidades ou ilegalidades perante o Tribunal de Contas (art. 74, § 2\%);

8. participação do produtor e trabalhador rural no planejamento e execução da política agrícola;

9. participação da sociedade e dos Poderes Públicos nas iniciativas referentes à seguridade social (art. 194);

10. caráter democrático e descentralizado da gestão administrativa, com participação da comunidade, em especial de trabalhadores, empresários e aposentados na seguridade social (art. 194, VII), reafirmado com relação à saúde (art. 198, III) e à assistência social (art. 204, II);

11. gestão democrática do ensino público (art. 206, VI);

12. colaboração da comunidade na proteção do patrimônio cultural (art. 216, $\left.\S 1^{\circ}\right)$.

Se forem analisados os vários instrumentos de participação, poder-se-á verificar que existe uma gradação, que vai desde o simples direito à informação, passando pelos instrumentos de controle, até a atuação direta do cidadão em órgãos integrantes da Administração Pública. 
Com efeito, o direito positivo exige:

1. motivação dos atos administrativos, para assegurar a transparência dos motivos e finalidades e permitir o seu conhecimento e impugnação pelos órgãos de controle e pelos próprios interessados;

2. princípio do contraditório em qualquer tipo de procedimento administrativo em que se estabeleça litígio entre Administração e administrado, o que exige, pelo menos, conhecimento dos autos, direito de resposta e possibilidade de recurso às instâncias superiores;

3. direito de denunciar irregularidades perante o Poder Público, que, no Brasil, pode ser exercido, dentre outros, perante o Ministério Público, o Tribunal de Contas, as Comissões do Congresso Nacional, isto para não falar em ouvidores-gerais instituidos por alguns Estados e Municípios;

4. direito de provocar o controle jurisdicional, não só por meio de ações individuais, como também e principalmente por meio de ações coletivas, que visam proteger interesses públicos, coletivos ou difusos; é o caso do mandado de segurança coletivo, da ação popular e da ação civil pública;

5. direito de participar de órgãos administrativos, seja de consulta, seja de deliberação, hipótese em que o cidadão, embora mantendo a sua situação de cidadão sem qualquer vínculo de emprego com a Administração Pública, participa diretamente das decisões administrativas.

\section{PARTICIPAÇÃo EM ÓRGÃos de CONSULTA}

A consulta é um procedimento que surgiu nos regimes autoritários, porque o monarca, tendo de decidir sozinho, acabava por se cercar de conselheiros. Depois de instaladas as demooracias, manteve-se o procedimento da consulta, mediante a criação, junto à Administração Pública, de inúmeros órgãos consultivos (conselhos, comissões, grupos de trabalho, comitês), alguns com funcionamento permanente, outros provisórios, mas sempre contando com representantes da sociedade.

A Constituição Federal prevê um órgão dessa natureza - o Conselho da República - que, entre seus integrantes, conta com seis cidadãos, sendo dois eleitos pelo Senado, dois pela Câmara dos Deputados e dois nomeados pelo Presidente da República (art. 89). Trata-se de órgão superior de consulta do Presidente da República, com competência para pronunciar-se sobre intervenção federal, estado de sítio, estado de defesa e outras questões relevantes para a estabilidade das instituições democráticas.

$\mathrm{Na}$ legislação ordinária há previsão de vários conselhos, como o Conselho Nacional de Educação, o Conselho de Defesa dos Direitos Humanos, 
- Conselho Tutelar, os Conselhos de Saúde, etc. As universidades públicas também contam, em seus órgãos colegiados, com representantes do corpo docente, do corpo discente e dos funcionários, às vezes com funções opinativas, outras vezes com funções decisórias. Também os órgãos responsáveis pelo processo administrativo tributário exercem funções consultivas e decisórias.

Quando tais órgãos exercem função meramente consultiva, eles emitem opiniões, pareceres, laudos, que não contêm propriamente uma decisão, uma manifestação de vontade; em grande parte dos casos, suas opiniões não vinculam a autoridade que vai proferir a decisão.

No entanto, mesmo quando $o$ ato que produzem não seja vinculante, não há dúvida de que, com a exigência, hoje amplamente reconhecida, de atendimento ao princípio da motivação, tais pareceres, quando acolhidos pela autoridade competente para decidir, fazem parte integrante do ato decisório. $E$, se não acolhidos, estará a autoridade obrigada a dizer as razões dessa decisão, apresentando a sua própria motivaçăo.

Além disso, existem hipóteses em que a manifestação do órgão consultivo é vinculante para a Administração; isto ocorre quando a competência desse órgão envolve matéria técnica, que exige conhecimentos especializados a respeito dos quais a autoridade competente para decidir não tem condições de manifestar-se. Nesses casos, mesmo que a autoridade esteja, aparentemente, diante de uma decisão discricionária, ocorre, na realidade, a chamada discricionariedade técnica, que não envolve mais de uma opção para a Administração. Por exemplo, se um órgão técnico como o Conselho de Defesa do Patrimônio Histórico e Artístico Nacional opinar no sentido de que determinado bem não possui valor para fins de tombamento, essa decisão vincula a autoridade, que não poderá efetuar o tombamento, porque lhe falece competência para decidir de outro modo.

É só pelo exame da lei, em cada caso, que se pode concluir se a manifestação de um órgão consultivo, de que participem representantes da sociedade, é ou não vinculante para a Administração Pública.

Mesmo que não exista essa vinculação, a só existência de órgãos desse tipo é importante para aproximar a Administração Pública do administrado. Como diz Jean-Pierre Ferrier (in "La participation des administrés aux décisions de l'administration", in Revue du Droit Public, n. 3, p. 684), "o que muda é a natureza das relações entre a Administração e os administrados; lá reside, justamente, o interesse da participação. Pela consulta, tenta-se associar à ação administrativa os representantes dos interesses privados para chegar à integração das forças coletivas nas instituições públicas. Esta integração, esta colaboração, é necessária a um funcionamento normal da democracia".

O grande problema dos órgãos de consulta é o da sua real representatividade. Para que esse caráter fosse assegurado, seria necessário que seus 
integrantes fossem eleitos pela própria sociedade representada e, de preferência, entre pessoas estranhas ao corpo dos Poderes do Estado, o que nem sempre acontece. De qualquer forma, os órgãos de consulta podem desempenhar um papel muito importante em especial quando suas conclusões são vinculantes para a Administração; mas, mesmo quando isso não ocorre, hipótese em que a sua existência é apenas formal, eles ainda contribuem para a maior aproximação entre a Administração e o particular.

\section{PARTICIPAÇÃO EM ÓRGÃOS DECISÓRIOS}

Além da participação em órgãos de consulta, é possivel também a participação do cidadão em órgãos de decisão integrantes da Administração Pública. Trata-se da chamada co-gestão.

Em muitos casos, os mesmos órgãos que exercem algumas funções consultivas dispõem também de competência decisória, como ocorre com o Conselho Nacional de Educação, o Conselho Tutelar previsto no Estatuto da Criança e do Adolescente (eleito pelos municipes), os colegiados, das Universidades, os Conselhos de Saúde, o Conselho de Contribuintes, etc.

A própria Constituição Federal prevê várias hipóteses de gestão democrática: na seguridade social (arts. 194, parágrafo único, VII, 198, III, e 204, II), na educação (art. 206, VI), na fixação da política agricola (art. 187), na proteção do patrimônio cultural (art. 216, § 1\%).

Não há dúvida de que muitos dos órgãos de participação encontram dificuldades, quer para sua instituição e instalação, quer para seu adequado funcionamento, quer para ver respeitadas as suas decisões.

Isto ocorre por razões várias. Em primeiro lugar, porque, na Constituição brasileira, a participação está prevista em normas programáticas, que dependem de iniciativas a serem adotadas posteriormente, seja pelo Poder Legislativo, seja pela própria Administração Pública. E, como diz Mariano Baena de Alcázar ("Curso de Ciencia..." cit., pp. 392/393), os políticos que estão no poder não têm interesse no surgimento de novos grupos participativos, pois isto significaria consagrar o estabelecimento de poderes rivais aos seus próprios; normalmente, reclamam a sua criação e se utilizam desses órgãos enquanto estão na oposição, porém perdem todo o interesse neles quando chegam ao poder.

Além disso, é grande 0 apego dos governantes às formas autoritárias de decidir, de cima para baixo, de dentro para fora, e sob influência, quando muito, dos grandes grupos de pressão.

E o problema de representatividade mencionado em relação aos órgãos de consulta pode existir em relação aos órgãos de decisão. 
Mas os órgãos colegiados que contam com participação de representantes da sociedade são hoje uma realidade, alguns deles já de longa data. Impõe-se, portanto, tratar do aspecto referente à natureza de suas decisões. E muitos são colocados fora da hierarquia administrativa, com ampla margem de independência, porque exercem atribuições outorgadas com exclusividade, que não podem ser delegadas a outros órgãos ou avocadas por autoridades superiores.

A questão que se coloca é a de saber até que ponto as decisões proferidas por esses órgãos são vinculantes, quer para a própria Administração Pública, quer para os administrados destinatários dos atos.

Sabe-se que os atos administrativos têm os atributos da presunção de veracidade (pelo qual se presumem verdadeiros os fatos neles alegados), da presunção de legalidade (pelo qual se presume a conformidade com a lei), da imperatividade (possibilidade de criar obrigações por decisão unilateral, independentemente de concordância do destinatário) e auto-executoriedade (possibilidade de execução, sem necessidade de título fornecido pelo Poder Judiciário).

Indaga-se então se esses mesmos atributos estão presentes nos órgãos que contam com participação popular. A resposta só pode ser afirmativa, desde que tais órgãos tenham sido criados por lei, que thes defina $o$ âmbito de atribuições.

A competência para a prática de atos administrativos decorre do direito positivo e não está necessariamente ligada à investidura em cargos ou empregos públicos. Já foram mencionadas, na parte inicial deste trabalho, algumas formas de colaboração entre particular e Poder Público, como ocorre com os concessionários de serviços públicos, notários, tradutores públicos, intérpretes oficiais, etc.

Em todas essas situações há dois elementos: um elemento público, que diz respeito à atividade; por outras palavras, a atividade que se exerce é uma atividade pública; e há um elemento privado, que diz respeito ao sujeito que presta essa atividade, pois ele é um particular que não tem qualquer vínculo empregatício com a Administração Pública. Em decorrência desse duplo aspecto, surgem também determinadas peculiaridades: uma primeira seria o fato de que esses particulares têm o dever de desempenhar um serviço público, sujeitando-se, inclusive, ao poder disciplinar da Administração Pública, que pode impor a eles determinadas sanções; mas, paralelamente, eles têm também o direito de desempenhar essas atribuições sem interferências indevidas da Administração Pública.

Uma outra peculiaridade está no fato de que, em se tratando de execução de serviço público, os atos jurídicos praticados por esses particulares têm a natureza de atos administrativos, com todos os apontados atributos. 
A diferença entre a primeira forma de colaboração (concessão de serviços públicos e outras) e a participação popular em órgãos colegiados da Administração está no fato de que, naquela, a atividade vai ser prestada por particulares fora dos quadros da Administração Pública e, nesta, o particular é chamado a integrar um órgão da Administração Pública. Mas, em uma hipótese e outra, os particulares agem por força de competência outorgada por lei, e seus atos se revestem das mesmas caracteristicas dos atos praticados por agentes investidos em cargos, empregos ou funçōes.

Sabe-se que as decisões proferidas por órgãos colegiados são denominadas deliberações e têm a mesma força obrigatória de um órgão singular; a sua força decorre da lei e não diminui pelo fato de o órgão contar, entre seus membros, com representantes da sociedade. Como ensina Hely Lopes Meirelles, as deliberações, "quando expedidas em conformidade com as normas superiores são vinculantes para a Administração e podem gerar direitos subjetivos para seus beneficiários" (in "Direito Administrativo Brasileiro", São Paulo, Revista dos Tribunais, 1985, p. 141).

As medidas administrativas e judiciais cabiveis para impugnação a esses atos são as mesmas cabiveis em relação a outro ato administrativo qualquer, praticado por servidor público; e as medidas cabiveis para impor a sua observância àqueles que se recusem a cumpri-los também são as mesmas. Até porque tais atos são praticados não por particulares, mas por um órgão colegiado integrante da estrutura administrativa do Estado. A decisão que se contém na deliberação do órgão colegiado expressa a vontade de um órgão e não a de seus componentes individualmente considerados.

A conclusão, portanto, quanto aos órgãos colegiados constituídos com participação popular é no sentido de que alguns exercem funçōes meramente consultivas, e, nesse caso, as suas manifestações podem ou não ser vinculantes para a autoridade competente para decidir, em função do caráter mais ou menos técnico da competência que exercem; outros exercem funções decisórias, tomadas por meio de deliberações que possuem todos os atributos dos atos administrativos, por decorrerem de competências outorgadas pelo direito positivo e serem praticados por órgão que faz parte integrante da estrutura administrativa do Estado.

A sua independência será tanto maior quanto melhor for assegurada a liberdade na escolha dos representantes pela própria comunidade representada e quanto mais o órgão estiver fora da hierarquia administrativa, recebendo um rol de competências exclusivas expressamente previstas no direito positivo. 